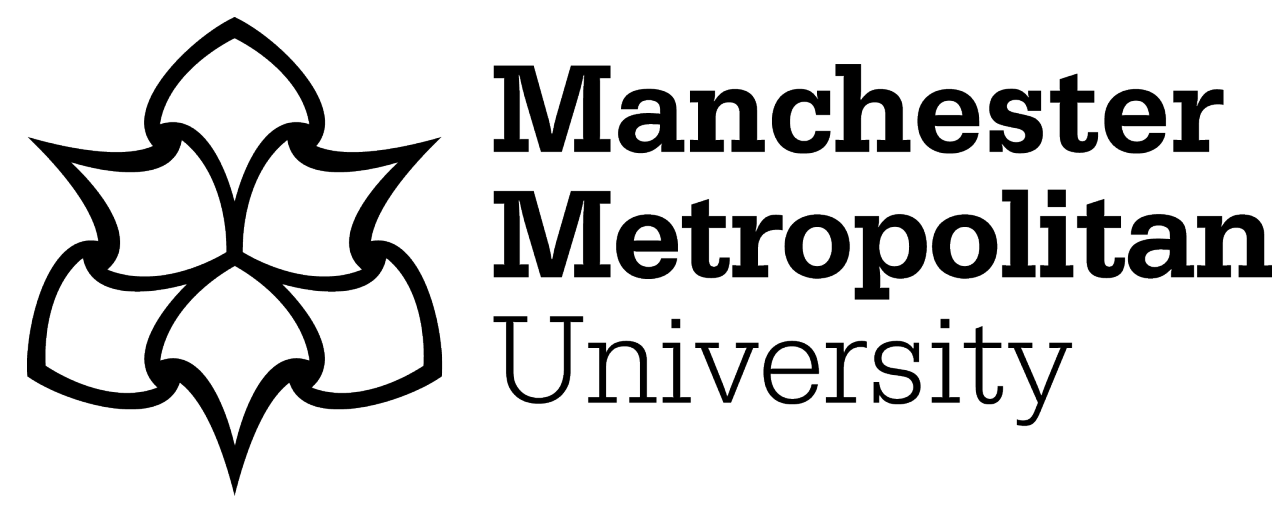

Rousell, David (2018) Walking with Media: Towards a mixed reality pedagogy in university learning environments. In: People, Personal Data, and the Built Environment. Adaptive Architecture . Springer. ISBN 9783319708744

Downloaded from: https://e-space.mmu.ac.uk/621320/

Version: Accepted Version

Publisher: Springer

Please cite the published version 


\title{
Walking with Media: Towards a mixed reality pedagogy in university learning environments
}

\author{
David Rousell, Manchester Metropolitan University \\ 53 Bonsall St, Manchester M15 6GX \\ d.rousell@mmu.ac.uk
}

\begin{abstract}
Recently the fields of architecture, media studies, and education have begun to converge through the proliferation of mixed reality technologies and interfaces. This convergence is widely described as offering new opportunities for immersive, seamless, decentralised and environmentally distributed learning experiences. This chapter contributes to a growing body of research exploring the transformation of learning environments through distributed media networks, digital databases, and innovative pedagogical interventions. It develops a theoretical framework for researching the interconnections between the built environment, mixed reality technologies, and place-based learning experiences and pedagogies. The second part of the chapter focuses on the development of the CubeWalk network, which involved a series of site-specific architectural installations, digital interfaces, and pedagogical interventions on a university campus in NSW, Australia. Two case studies are presented which describe the co-design and evaluation of mixed reality tutorial walks across the university campus. Drawing together insights rendered through the case studies, the chapter offers a series of theoretical propositions for a 'mixed reality pedagogy' that operates through $21^{\text {st }}$ century learning environments and media networks.
\end{abstract}

Keywords: learning environments; higher education; $21^{\text {st }}$ century media; learning design; mixed reality; personal data

\section{Introduction}

In recent years the fields of architecture, media studies, and education have found common ground through the proliferation of locative media technologies and augmented reality interfaces, among other mixed reality technologies and applications. This convergence is widely described as offering new opportunities for immersive, seamless, decentralised and environmentally distributed learning experiences (Baran, 2014; Ho et al, 2011; Rousell, 2016; Sharples et al, 2009). Locative media applications associated with augmented reality, geocaching and smart objects offer new resources for co-designing and implementing contextual and mobile learning experiences in higher education (Bacca et al, 2014). Recent studies have also shown that mobile approaches to teaching and learning have been effective in integrating digital, place-based and embodied learning experiences across disciplines (e.g. Bower et al, 2014; Rousell, 2015). A number of previous studies have, for instance, explored the digital augmentation of outdoor learning environments (Rogers et al, 2004); engagement with historical spaces and events through mixed reality (Stanton 
et al, 2003); and posthuman co-figurations of learning through geolocative media (Kiefer-Boyd et al, 2018).

Peters and Besley (2013) have described the turn towards such 'mixed reality' learning environments in higher education as gesturing towards an emerging figure of the 'creative university'. For these authors, the $21^{\text {st }}$ century digitisation and decentralisation of the university holds significant opportunities for more democratic and imaginative forms of educational practice which emphasise 'theories of collaboration, collective intelligence, commons-based peer production and mass participation in conceptions of open development' ( $\mathrm{p}$. $\mathrm{x}$, emphasis in original). However, the conceptual, ethical, and pedagogical implications of such mixed reality learning environments remain 'scarcely reported' in the field of education (Baran, 2014, p. 17). Little is known about the ways that mixed reality learning environments impact on the experiences of students, and the elicitation, archiving and deployment of personal data within such learning environments remains ethically problematic. There is also a need for innovative pedagogical frameworks that respond to the affordances of $21^{\text {st }}$ century learning environments and media networks in relation to specific practices, concepts, and contexts of teaching and learning (Bacca et al, 2014; Ho et al, 2011; Oliver, 2011).

This chapter responds to these international calls for the development of pedagogical theory that integrates the affordances of the built environment and new media technologies with everyday practices of teaching and learning in the university. The first part of the chapter focuses on the development of a theoretical framework for understanding the environmentally distributed connections between learning, the built environment, and new media technologies. This includes the development of a relational theory of learning environments, and the contextualisation of this theory within the broader field of educational architecture in the $21^{\text {st }}$ century. The second part of the chapter focuses on the development of the CubeWalk network, which involved a series of sitespecific architectural installations, digital interfaces, and pedagogical interventions on a university campus in NSW, Australia. This part of the chapter draws on case studies from the Walking With Media project (2015-2016), which involved the co-development of tutorial walks using augmented reality to connect digital media archives with physical objects, maps, concepts and locations. Through the analysis of evaluation data from the Walking with Media project, the chapter's findings support the use of mediated architectural interventions to transform teaching and learning practices in specific places and institutional contexts. The chapter concludes by framing this convergence of the built environment, immersive technologies, and learning within a 'mixed reality pedagogy', while also gesturing towards further research into the changing role of the educator in relation to $21^{\text {st }}$ century media networks and architectures.

\section{Part 1: Learning, Media, and the Built Environment}

The field of educational architecture is increasingly understood as central to the creation of learning environments that are responsive to the social, technological, and environmental changes 
of the $21^{\text {st }}$ century (de Freitas, 2011; Gislason, 2010; Hall, 2017; Leiringer \& Cardellino, 2011; Rousell, 2016; Woolner et al, 2010). The recent turn towards the pedagogical affordances of the built environment aligns with long-standing international initiatives for educational transformation through the improvement of school and university buildings, campuses, landscapes, and facilities (OECD, 2006; Hertzberger, 2008; Willis, 2017). Digital technology and new media have figured prominently within future-oriented educational aspirations, as demonstrated through programmes such as FutureLab (NFER, 2017) and BECTA in the UK (Livingstone, 2012).

Increasingly, technology-enhanced learning spaces are seen as vehicles for delivering personalised learning, affording spatial and cognitive 'flexibility' and providing equitable access to wider information sources, while also yoking individual student performance to monitoring and evaluation through the distributed operations of 'big data' (Dovey \& Fisher, 2014). The issue of how personal data is elicited, archived, and deployed in $21^{\text {st }}$ century learning environments has become both salient and controversial, as schools and universities are now able to collect vast amounts of data about students and staff under decentralised regimes of neoliberal corporatisation and managerialism (Rousell, 2016). While such data is often collected under the auspices of 'personalisation', 'improvement' and 'enhancement' of teaching and learning, such practices increasingly resemble the continuous exchange of intimate personal data for 'service provision' in the social media industry. As such, the corporate decentralisation of the university and the emergence of mixed reality learning environments open up new opportunities for creativity, collaboration, and mobility, while at the same time introducing new modes of social control and co-option through the capture and manipulation of personal data.

\section{Learning and Architecture}

Despite recent future-reaching ambitions to enhance university learning outcomes through improvements to the built environment and associated data infrastructures, such initiatives often reflect a policy landscape that views learning environments as 'mechanisms' for the provision of neoliberal education opportunities (Jacobs, 2015). Such mechanistic approaches to architectural improvement and transformation are seen to operate as closed systems which impose predetermined design principles and values on school communities from the outside (Woods, 2017). As such, some architectural initiatives have suffered from the lack of research methods, theories, and evidence that adequately account for the interpenetrating factors of school building design, embodied educational practices, and $21^{\text {st }}$ century media technologies (Gislason, 2010; Leiringer \& Cardellino, 2011). As Gislason argues:

There is indeed no established framework for conducting school design research, and there have been few studies of how school architecture shapes educational practice. The underlying problem in this regard is that researchers generally consider teaching and learning apart from their architectural setting, or study the built environment separately from classroom practice. (2010, p 127) 
As a result of this apparent gap between architectural and educational practices, a growing body of research argues for new models of co-design that are responsive to the relations between the built environment, emerging technologies, and everyday teaching and learning experiences in diverse educational spaces (Hall, 2017). There is a need for studies that explore how architectural visions can productively engage with curriculum and pedagogy, and more broadly, with the lives, habits and expectations of students, lecturers, school staff and local communities (Gislason, 2010). As Hall (2017, p. 324) suggests, the focus of educational architecture needs to be expanded beyond the school building itself, to include the ways that 'design becomes enacted, experienced, and lived across indoor and outdoor learning spaces and...how schools physically connect to and reflect other important educational sites'. This gestures towards what Massumi (2011, p. 53) has termed a "relational architecture" which is orientated towards the experiential and speculative potentials of the built environment as a modality for collaborative design, social transformation and creative expression.

Rather than seeing the built environment as a mere container for human activity, the notion of a relational architecture reconceptualises the university campus as a 'distributed architecture of experience' (Massumi, 2011, p. 53). This reflects a substantial theoretical expansion of how learning environments can be conceived, constructed, experienced, and understood in relation to $21^{\text {st }}$ century media technologies and personal data. In higher education, the academic learning environment has traditionally referred to the physical spaces in which teaching, learning and research take place within a university campus. These environments often include places like studios, laboratories, lecture theatres, classrooms, libraries and common outdoor spaces. More recently, academic learning environments have extended into digital spaces that can be accessed regardless of geographical location, as well as external public spaces such as galleries, museums, botanic gardens and national parks. Yet the learning environment can be understood as much more than the physical, geographical or even digital location in which learning takes place; it also refers more broadly to 'the set of conditions that enable and constrain learning' (Brown, 2009, p. 16). In thinking beyond the normative conception of the built environment as a physical container for human activity, the learning environment comes to include the messy, contingent, and experiential dimensions of learning as a dynamic and relational process. As Brown further explains, learning environments are open, mobile systems with porous borders that are responsive to both internal and external dynamics, allowing them to evolve morphogenetically over time (p. 16). By thinking through a relational (rather than a mechanistic) theory of architecture, learning environments are understood as massively distributed ecological networks of people, data, places, times, buildings, concepts, thoughts, practices, technologies, materials, plants, feelings, stories, interactions, and more. 


\section{Atmospheric media}

A relational architecture re-imagines the learning environment as a medium or milieu that simultaneously constrains and affords the potentials for ecological growth, learning, and development. Such a reconceptualization becomes increasingly necessary as $21^{\text {st }}$ century media technologies such as WiFi, GPS, microsensing, and mobile computing become ubiquitous elements of everyday life. The architectural surfaces of walls, screens, and objects become permeable and plastic in their capacities to mediate the molecular, biochemical, and semiotic 'trafficking' of data across the porous membranes of human bodies and cells (Frost, 2016). WiFi signals, for instance, pass through the walls of buildings and human tissue alike, respecting no fixed boundary between body and environment, nature and culture, inside and outside, or subject and object. Seemingly opaque surfaces such as bodies and walls are now understood to be transparent, opening onto a more widely distributed ecology of sensory data. As Parisi (2009) argues, the environmental distribution of sensory connections between living bodies, buildings, and digital media is more than a computational network that simply processes 'information'. Rather, Parisi conceptualises these architectural networks as 'technoecologies of sensation' which achieve a collective nexus of sensibility and dynamic response that moves seamlessly 'between organic and inorganic matter' (p. 192). Dynamically mediated streams of sensory data become diffuse, elemental, and atmospheric rather than remaining tied to individual bodies and personalities (de Freitas, 2018). As a hallmark of this posthuman condition, we find personal data taking on an environmental character within $21^{\text {st }}$ century media ecologies, and that this depersonalisation of data corresponds with a radically environmental account of human learning, sociality, experience, and subjectivity (Hansen, 2015; Simondon, 2017; Whitehead, 1978).

One of the drivers of such an atmospheric reading of $21^{\text {st }}$ century media technologies is the recognition that these technologies do most of their work outside the narrow bandwidth of human perception. In many cases, the technical operations that digital technologies use to sense, calculate, and mediate our environments do not correspond with human sense perception or cognitive capacities at all. Hansen (2015) describes how $21^{\text {st }}$ century media technologies operate at microtemporal processing speeds that take place 'above and below' the thresholds of human consciousness and sense perception. Rather than being prosthetic extensions of human embodiment and perception, digital media technologies physically and directly transform the environment by altering its 'causal infrastructure' and reconfiguring the conditions under which human sense experience becomes possible (p. 38). This is because media technologies 'impact the environment - including our bodily environment - before impacting ... our higher-order sensory and perceptual faculties' (p. 38). For both Parisi (2009) and Hansen (2015), media technologies are seen to environmentally mediate, reconfigure, and co-produce the sensible conditions under which learning takes shape in the 21 st century. Media thus take on a new figuration as atmospheric, elemental, and distributed agential forces which are not reducible to anything that humans can directly sense, perceive, or know. 


\section{Radically environmental theories of learning}

In responding to these recent reconceptualisations of $21^{\text {st }}$ century media and architectural space, this chapter contributes to associated theories of learning as environmentally distributed. Drawing on relational conceptions of subjectivity and experience in process-relational philosophy (Deleuze, 1994; Guattari, 2008; Simondon, 2017; Whitehead, 1978), psychology (Gibson, 1979; Winnicott, 1987), and biology (Margulis, 1999; Protevi, 2013), learning is understood as a process that is distributed across heterogeneous qualities, forms, forces, and potentials of collectively inhabited environments and sensory milieus. Rather than locating learning 'inside' an individual body or mind, this chapter engages more closely with the relational, sensory, and affective externality of learning as a emergent function of a collective environmental manifold (de Freitas, 2018; Rousell, 2017; Rousell \& Fell, 2018). This radically environmental theory of learning is increasingly supported by recent findings in the life sciences, which exhibit the dynamic porosity and plasticity of biological, social, genetic and percepto-motor functioning (Frost, 2016; Margolis, 1999; Youdell, 2017).

As the life sciences continue to demonstrate the dynamic 'trafficking' of biochemical, genetic, energetic, and semiotic information across the porous membranes of human bodies, theories are emerging which emphasise the overarching primacy of the environment in conditioning the very possibilities of life, thought, growth, development, interaction, and learning (Frost, 2016). Emerging theoretical models of learning thus propose a dynamic and reciprocal relationship between humans and the environments they co-inhabit with a multitude of others, as mediated by the material and social affordances of architectural spaces, pedagogical interactions, and media technologies (Rousell, 2016). Rather than being reduced to the cognitive operations of the individual human mind, learning is conceived as an environmental, pre-cognitive, and transindividual process that can never be determined in advance of its occurring (Deleuze, 1994; Simondon, 2017).

\section{Learning Through Transitional Space}

The work of Elizabeth Ellsworth (2005) has been seminal in analysing the dynamic relationships between pedagogy, media, and architecture through relational theories of learning as processual, affective, and environmentally distributed. Ellsworth draws extensively on Winnicott's (1989) concept of 'transitional space' in order to analyse the anomalous places of learning created by artists, architects and designers such as Maya Lin, Suzanne Lacy and Frank Gehry. Transitional space, as Winnicott describes it, is a spatio-temporal process that puts inner and outer worlds into relation through playful inquiry and experimentation (Ellsworth, 2005, p. 60). The element of play is central to the concept of transitional space, as it is only through play that the passages and movements between inner and outer worlds can be activated, extended, explored and sustained. It is in this sense that architecture takes on a greater agency and importance in the fostering of 
learning experiences that 'mix' together social, conceptual, physical, spatial, affective, natural, and technological elements and realities.

Winnicott (1989) also thought of transitional space as potential space, as a virtual dimension of emergence and creation that is 'like a field of energies that have not yet been expended, or a reservoir of potentialities that have not yet been tapped' (Shaviro, 2009, p. 35). This means that transitional space requires some manner of participatory activation for its potentiality to be actualised. In this sense, transitional spaces can only exist in potential because 'nothing makes them inherently or inevitably transitional' (Ellsworth, 2005, p. 60). While an architect's or a teacher's design may hold within it the possibilities for transitional spaces to emerge, it is only through imaginative, immersive and inventive engagement on the part of the learner that these spaces actually come into being. The pedagogical implication, as Ellsworth (p. 32) notes, is that transitional spaces can be designed for, but not predetermined or forced into existence:

[A learning environment] holds the potential to become transitional space when it provides opportunities for us to both act in the world and be acted upon by it- while at the same time offering us the flexible stability we need to risk allowing ourselves to be changed by this interaction.

A transitional learning environment is a space that effectively holds or harbours the possibility conditions for transitional experiences to occur, often by surprise, speculation, and improvisational play. There can be no template or blueprint for what a 'transitional learning environment' should look like. Instead, Ellsworth suggests 'laying out desired qualities for the design of an environment that will not be complete or realised until and unless its users enter it and find their own uses for it' (p. 61). The transitional learning environment is thus constructed through a relational architecture of engagement though which various materials, ideas, media, technologies, tools, designs and principles can be assembled into new and unforeseen configurations. It is this dynamic mixture of inner and outer, human and nonhuman, social and biological, natural and cultural, somatic and technological realities that forms the basis for what I call a 'mixed reality pedagogy'.

\section{Part 2: The CubeWalk Network}

The first part of this chapter has attempted to assemble a theoretical framework which connects an environmental theory of learning with $21^{\text {st }}$ century media technologies, personal data, and the built environment. In the second part of the chapter, I describe the development and implementation of the CubeWalk network as one possible example of what such a 'mixed reality pedagogy' might look like in practice. As designed and created as part of my doctoral project between 2013-2017, the CubeWalk is a site-specific interactive artwork comprised of 12 glass cubes which have been installed in different locations across the Lismore campus of Southern Cross University in NSW, Australia. As commissioned and funded by the Vice Chancellor's Sustainability Fund, the CubeWalk draws on the natural and cultural affordances of the campus to create spaces for conceptual encounters and practical engagements with pressing issues associated with cultural and 
environmental sustainability. The overarching aim of the project was to provide opportunities for people of all ages to engage with the social and environmental challenges of our times, including the rapid acceleration of global climate change, catastrophic loss of biodiversity, social and economic injustice, and the rise of ubiquitous computation and bio-genetic technologies.

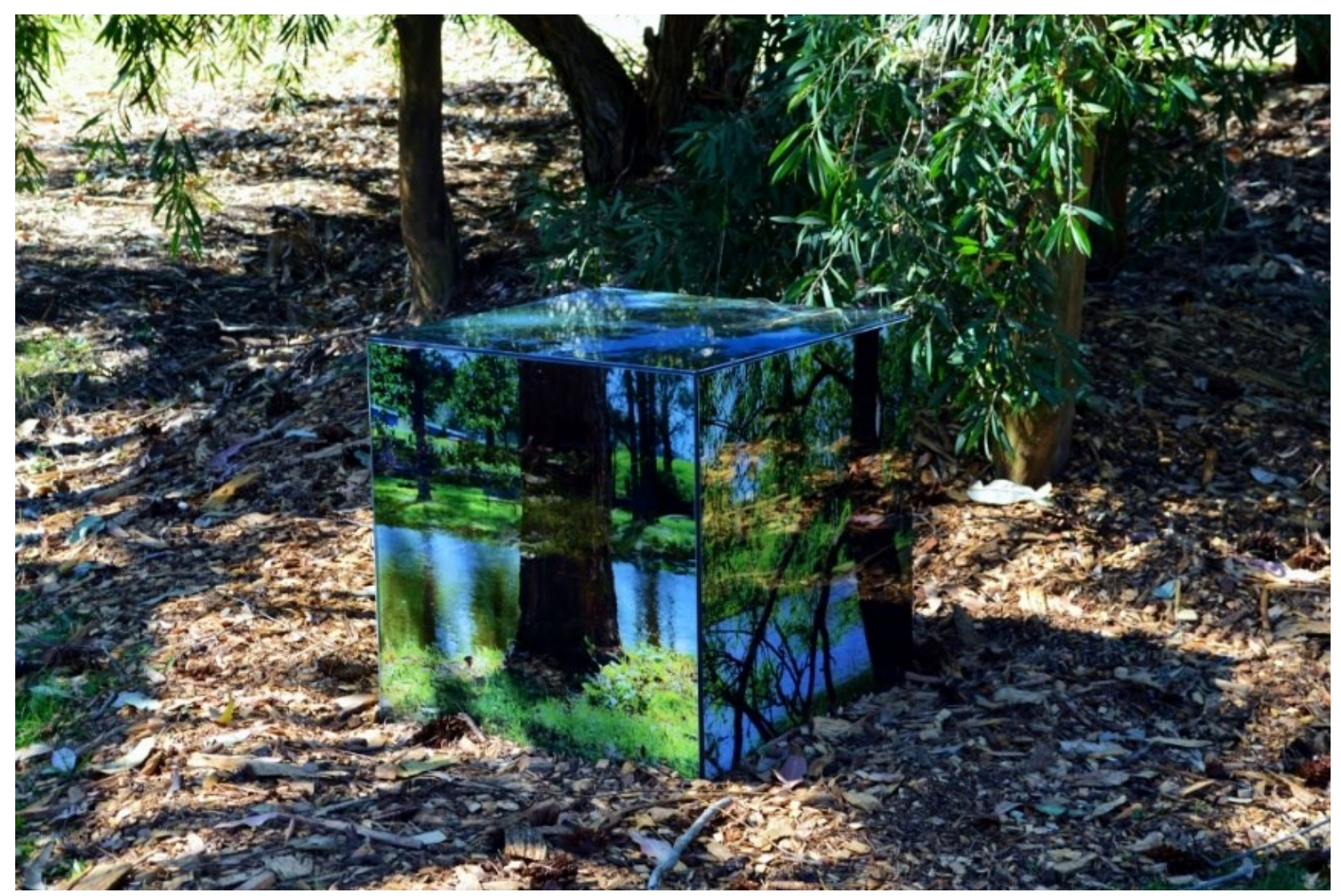

Figure 1: One of the cube's diffractive glass surfaces in relation to its environmental surrounds

The CubeWalk network was designed to intervene in both the physical and the conceptual infrastructure of the campus learning environments. The physical infrastructure of the campus was modified through the installation of 12 glass cubes in strategic and aesthetically compelling sites connected with specific disciplinary areas. The glass surfaces of the cubes were printed with digital images taken from the precise locations of each of the installations. This creates a continuous series of interactions between the surfaces of the cubes and the reflections of the surrounding environment, generating a dynamic series of interference patterns, or diffractions, which disrupt habitual patterns of movement, perception, sensibility, and learning (see Figure 1). Regardless of where you might be working or studying on the campus on a given day, you are more than likely to encounter at least one of the cubes as you go along your way. By diffracting the learning environment with its own reflection, each cube intervenes in the learning environment in order to render an alternative vision and sense of the university campus- a vision that specifically 
foregrounds and operationalises the 'mixed realities' of learning as an environmentally distributed process.

In addition to these physical interventions into the campus environment, the CubeWalk also intervenes in the conceptual landscape of the university by locating specific philosophical concepts in relation to each of the cubes. Each of these concepts are responsive to current challenges associated with environmental and cultural sustainability, including the issues of climate change, human-animal relations, biotechnological advances, the co-creation of futures, and the need for a more sensitive and ecological engagement with the natural world beyond the human. Figure 2 shows the distribution of concepts across the university campus, each of which also keys into the disciplinary territories and conceptual practices that occur in each location. For instance, the concept of 'becoming' was located in close proximity to the Gnibi College of Indigenous Studies; the concept of 'materiality' was located directly under the Chemistry labs; the concept of 'design' was located in the School of Engineering; and the concept of 'imagining' was located between the Visual Art, Film, and Music studios.

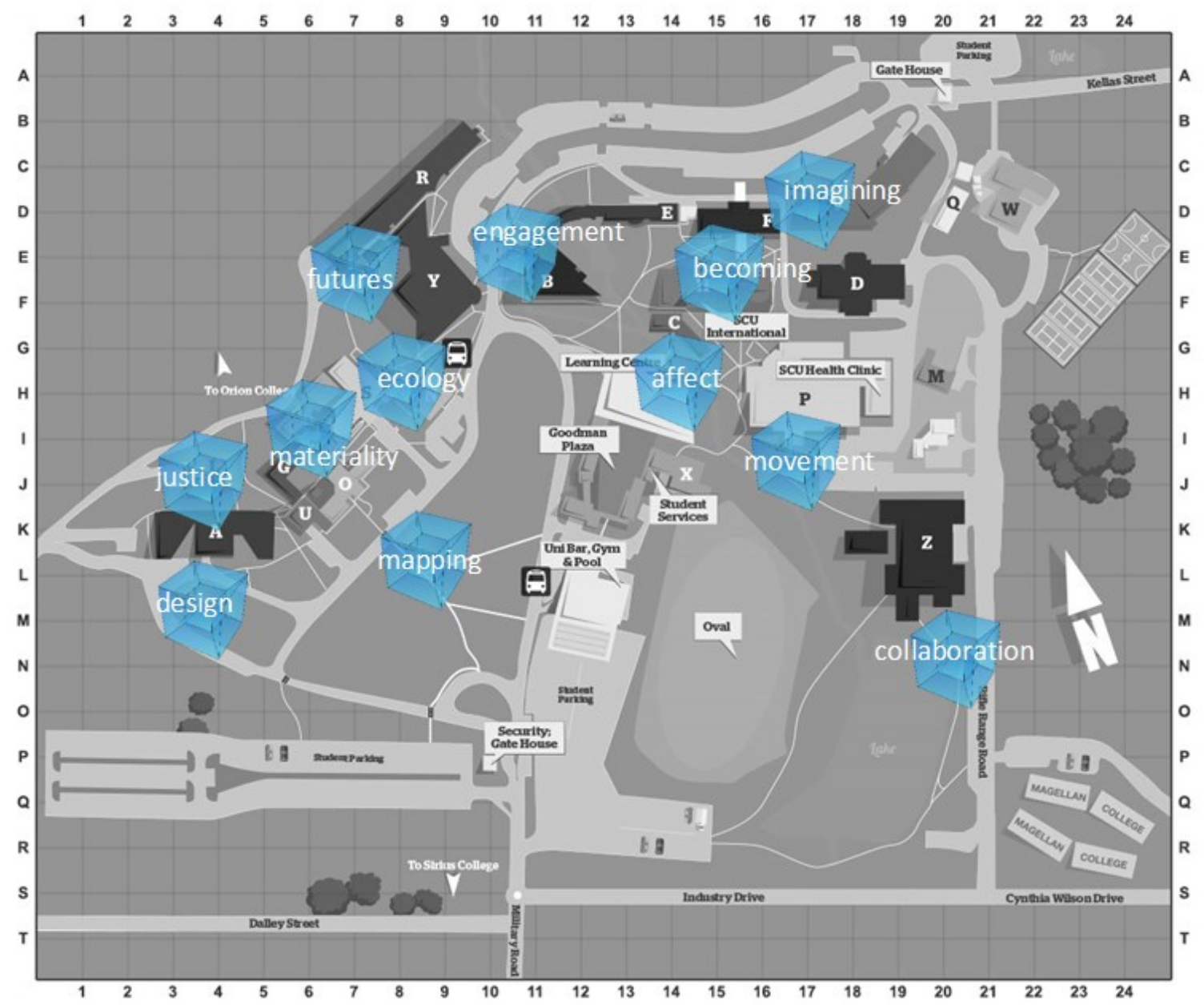

Figure 2: Map showing the distribution of artworks and concepts across the learning environments of the university campus 


\section{Digital Archiving and Multimedia Data}

This physical and conceptual re-imagining of the university campus has been extended through the use of digital technologies which create connections between human-generated media, the campus environment, and the cubes as architectural objects. Each of the cubes has been linked to an online interface and digital archive that engages students with multimedia content and activities in response to the concepts associated with each cube (see www.statesandterritories.org). Each concept theoretically provokes and conditions the digital content that is generated, as well as the learning activities that are undertaken in each location on campus. These interfaces include portals that enable students to submit audio, visual, or textual responses into digital archives linked to each cube and its geographical location. In this way, the physical surfaces of the cubes have been extended and augmented by digital technologies that enable new layers of multimedia data to be accessed and archived at each location over time (see www.statesandterritories.org/archives).

In this chapter, I refer to the data that people have generated and uploaded into the cube's digital archives as 'multimedia data' rather than 'personal data'. This reflects the theoretical position, as outlined in the previous section, that such data takes on an environmental and medial character when it becomes distributed within a sensory ecology or network. However, this move does not suggest a lack of concern with how people-generated data is generated, configured and appropriated within the network. In many cases, the data that people chose to create and upload to the network consisted of photographs, videos, artworks, animations, and sound recordings that included information that could be used to identify them personally. In other words, people chose to make their personal data public by uploading it into the network, and in doing so, they contributed to an environmentally distributed digital database that can be experienced by others into the future. For example, a Widjabul Indigenous elder named Aunty Irene Harrington contributed a richly layered sound work which is geolocated within the 'becoming' cube outside the Gnibi College of Indigenous Studies. Within the sound work she introduces herself by name, and then proceeds to articulate intimate stories and songs from her experience of growing up within that vey landscape, or 'Country' as she relates it. This example speaks to the radical environmentality of personal data as taken up within the CubeWalk network, as Aunty Irene's personal data is connected with and distributed across the data of Country as interwoven with Indigenous culture and history. Rather than being reducible to Western conceptions of the personal individual subject, data related to persons and identities are intricately connected with more widely distributed media ecologies that span multiple senses, bodies, cultures, spaces, temporalities, and modes of existence.

By linking the geographical spaces of the campus with conceptual and digital spaces opened up by digital interfaces and archives, the cubes have come to operate as triggers for mixed reality learning experiences combining multimedia data, place-based learning, and immersive media. Using an augmented reality application called Aurasma (Hewlett Packard, 2016), students are now able to freely walk the campus and activate a whole series of site-specific multimedia data and 
activities by aiming their phones or tablets at the surfaces of the cubes. The software uses an algorithm to recognise the image on the surface of each cube through the camera of a mobile device, thus triggering a series of interactive surfaces and layers of multimedia data. The Aurasma application also enables academics to digitally resurface the cubes with their own PowerPoint slides, images, videos, animations, and texts, essentially allowing the cubes to be reprogrammed as triggers for any number of mobile learning experiences (see Figure 3).
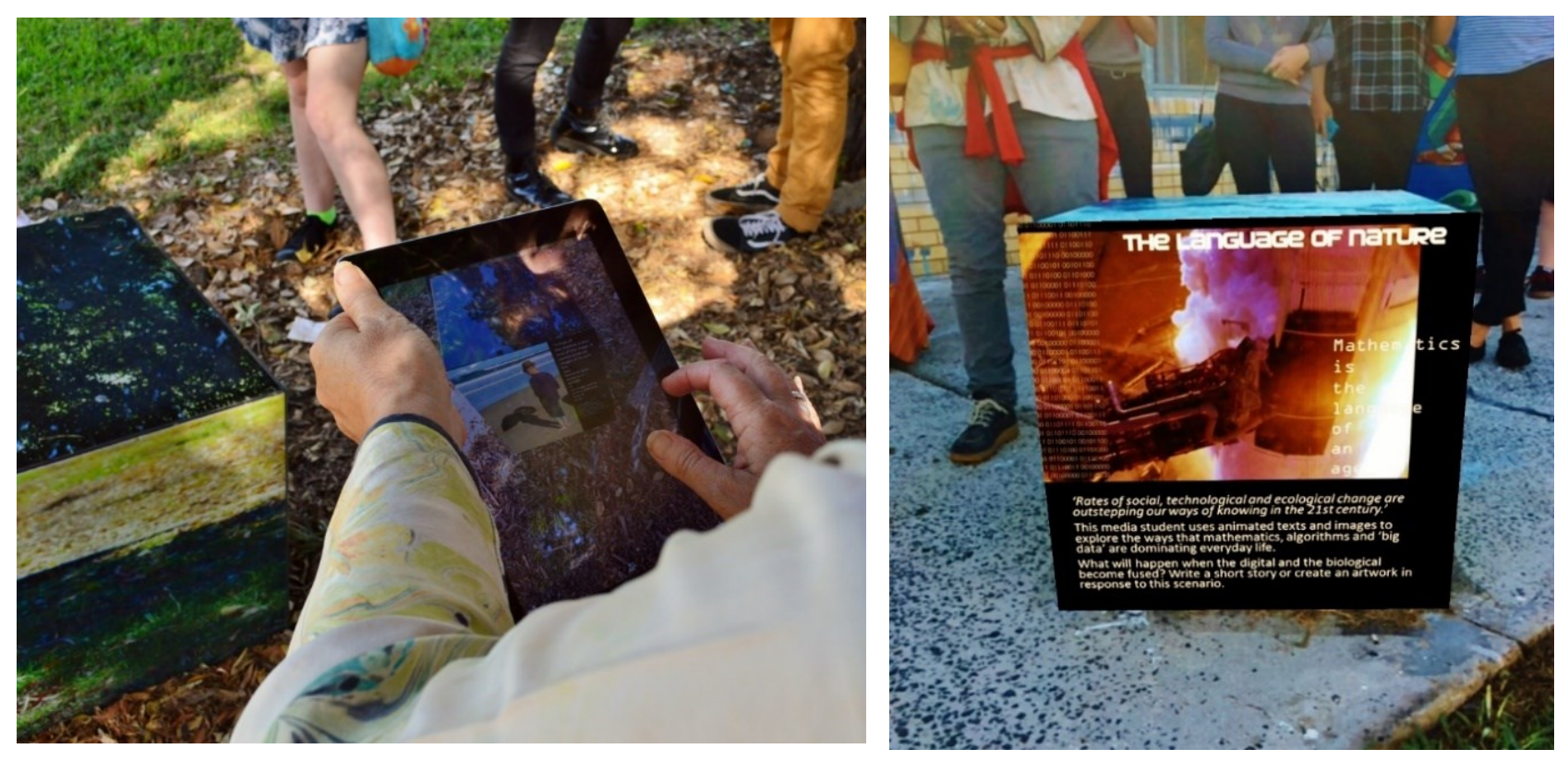

Figure 3: Archival content triggered by participating students using the Aurasma augmented reality application in conjunction with the CubeWalk network

\section{Information Flows Within the CubeWalk Network}

As the CubeWalk network has developed as a conceptual, architectural, and data infrastructure, new layers of user experience, interaction, and information flows have added to the complexity of the system. Figure 4 offers a basic system diagram that illustrates the five technical components of each cube in the network and the informational relations between them. The technical components are defined as a) the Associated Concept (AC), which conditions the forms of content and activity populating the entire system for each cube; b) the Immediate Environment (IE), which includes the geographical and disciplinary region surrounding the cube as well as the human and nonhuman interactions within that region; c) the Physical Cube (PC), which refers to the cube itself along with its diffractive surfaces; d) the Digital Archive (DA), which refers to the web-based interface and data archive associated with each of the cubes, and; and e) the Mobile Device (MD), in this case an iPad that is running the Aurasma augmented reality software application.

The diagram shows two structural relations that are implicit to the system itself, as denoted by black arrows: 1) the relation between the IE and the $P C$ as expressed through the diffraction of movement, sound, colour, and form on the surfaces of each cube; and 2) the relation between the 
$I E$ and the $D A$ as expressed by the local activities and multimedia data that are archived and accessed through that particular cube. In addition to these structural relations which are implicit to the design itself, a complex flow of information is enabled by the mediating function of the MD, in this case an iPad running Aurasma augmented reality software. As shown on the right side of the diagram, the MD enables the input and output of multimedia data from the DA via the IE, as well as the triggering and projection of data from the DA onto the surface of the PC. This essentially completes the reciprocal informational circuit by creating a dynamic relation between the AC, the PC, the DA, and the IE for each cube.

Associated Concept (AC) conditions the activities and the data in relation to the IE, e.g. Becoming, Affect, Materiality, Ecology, Futures, Imagining

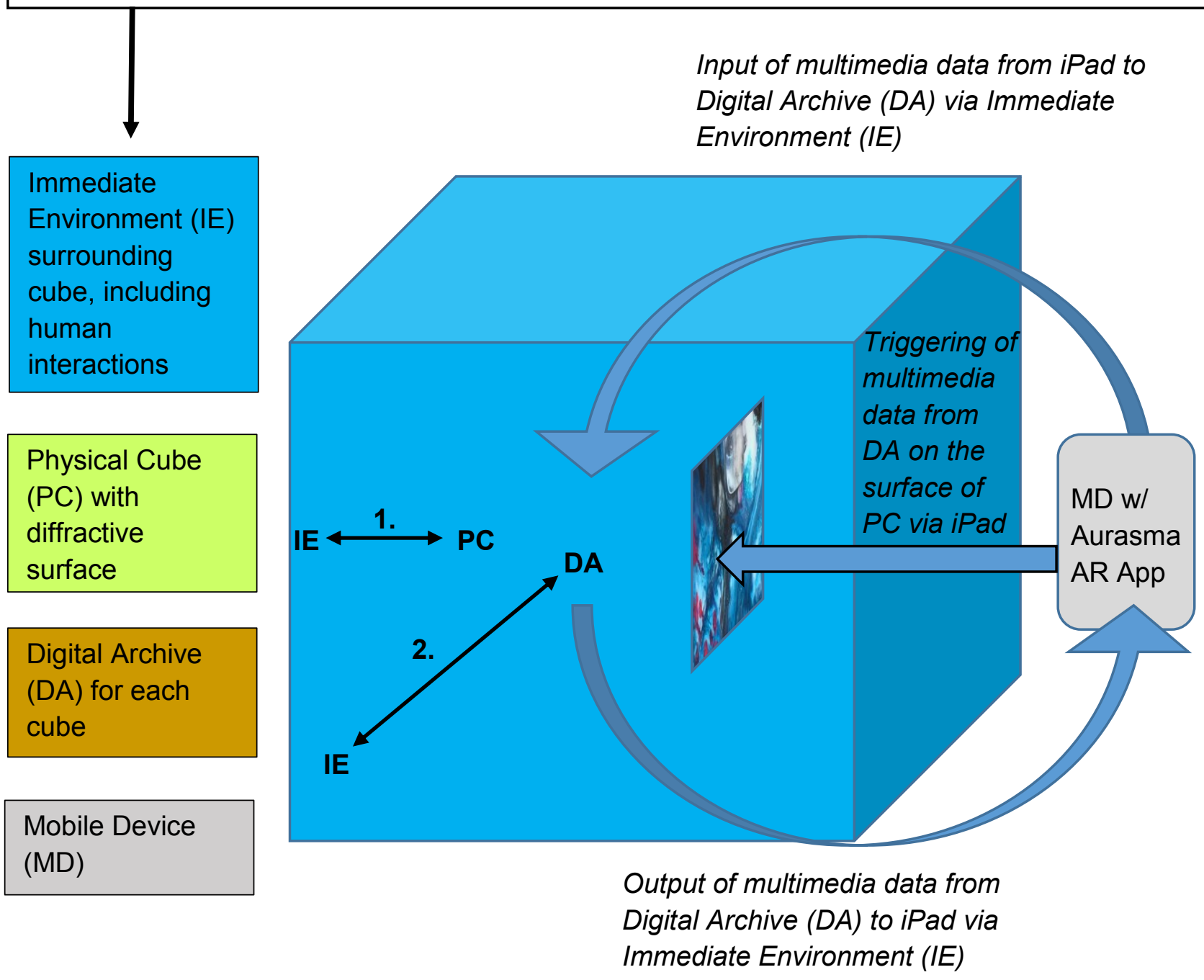

Figure 4: System diagram showing informational flows in relation to Associated Concept (AC), Immediate Environment (IE), Physical Cube (PC), Digital Archive (DA), and Mobile Device (MD) running Aurasma augmented reality software 
The question remains as to the informational exchanges between and across cube systems and their various components as diagrammed in Figure 4. While the CubeWalk network was designed to be upgraded with wireless communications between the cubes in possible future iterations, at the time of writing this networked operationality remains unrealised. The primary function of cross-cube informational exchange is therefore attributed to the activation of the network by human users, including the ability to perform walking-based perambulations between the twelve cubes; make connections between site-specific concepts, places, activities, and events; access the multimedia data archives either on-site or online through the project website; and configure the triggering and projection of multimedia data on any of the 60 diffractive surfaces shared across the twelve cubes. It is precisely these functions that are left to human users to facilitate which allow for the CubeWalk network to contribute to the development of a mixed reality pedagogy, as each cube/environment/concept/interface can be iteratively reconfigured to create an open-ended series of learning experiences which are distributed across the campus.

Over the last three years, the CubeWalk network has provided an infrastructure for developing interdisciplinary research initiatives and experimenting with new pedagogical and curricular frameworks for both coursework and community engagement. These innovations include a campus-wide Soundtrail that is now open to the wider public; mobile classrooms that use augmented reality to trigger learning experiences across disciplines; and digitally mediated orientation programs for new and prospective students. At the time of writing, over 200 undergraduate students and 20 lecturers have actively used the CubeWalk network for teaching and learning activities and contributed to the project's digital archives. These participants have hailed from a wide range of academic disciplines, including the visual arts, media studies, cultural studies, education, engineering, and the physical sciences. In the following sections, I focus on the implementation and findings of the Walking with Media sub-project which explored the applications of the CubeWalk network for enhancing teaching and learning in specific undergraduate units.

\section{Walking with Media (2015-2016)}

In 2015 I received additional funding from the Centre for Teaching and Learning to undertake a sub-project of CubeWalk called Walking with Media. The sub-project was designed to apply the conceptual, architectural and digital infrastructure of the CubeWalk to support teaching and learning across the university. More specifically, Walking with Media focused on the codevelopment of contextual and mobile learning designs that used the CubeWalk infrastructure to deliver core curriculum content in units across the arts, cultural studies, environmental sciences, and education. Central to the project was the exploration of augmented reality as a technical medium for distributing multimedia data across the university campus, using the network of cubes as conceptual touchstones and triggers for place-based learning activities co-developed by university lecturers. The key research questions guiding the Walking with Media project were: 
1. How might university lecturers use the CubeWalk network to enhance student engagement with course-related content, concepts, and activities?

2. How might mixed reality technologies support the development of effective teaching and learning experiences using the CubeWalk?

3. In what ways does student engagement with the CubeWalk network refute or support a theory of learning as environmentally distributed?

\section{Co-Design and Evaluation Methodology}

The research design for the Walking with Media project reflected the open-ended and exploratory nature of these questions, while also focusing closely on the need for a rigorous evaluation of student's experiences while engaging with the CubeWalk. The project was undertaken through a participatory design-based methodology which was orientated towards 'designing for educational possibilities' (Gutierrez, 2016, p. 187). Design-based research in education works to generate insights and build theory about learning through the development, prototyping, and evaluation of physical, social, and conceptual interventions into educational processes (Kelley, Lesh, \& Baek, 2008). This approach enabled me to work with lecturers in the arts, humanities and sciences to codevelop and prototype new learning activities in the form of 'tutorial walks' which aimed to enhance student learning through engagement with the CubeWalk. The participatory nature of this approach was crucial in establishing the conditions for effective collaboration across disciplines, including collaborations between myself, the lecturers who participated as co-researchers, and the students who trialed the walks and provided invaluable feedback. The Walking With Media project was organised across three stages of Co-design, Implementation, and Evaluation.

The Co-Design Stage involved the production of a co-design framework that effectively enabled lecturers to design 'tutorial walks' that embedded media, curriculum content, and activity prompts within specific regions of the university campus. Each tutorial walk used the CubeWalk network as a conceptual and architectural infrastructure for mapping specific itineraries across the campus, and triggering concepts, curriculum content and learning activities in specific locations using augmented reality technologies. The design framework guided lecturers through a sequential process of selecting specific cubes, concepts, geographical locations, media platforms, and multisensory data from the digital archives associated with each cube. The varieties of content included photographs, sound recordings, video recordings, texts, and artefacts that had been produced by students and lecturers over a period of two years. Lecturers could also source, create, and embed their own new curricular content at each cube location based on the learning outcomes of their specific units.

Once the design framework had been completed through a collaborative working group I organized a series of professional development 'walkshops' which introduced participating lecturers to the CubeWalk and the design framework. The 'walkshops' were attended by 10 lecturers representing a range of disciplines across the arts, humanities, and sciences. Each walkshop involved the on- 
site collaborative design of tutorial walks through the trialing of augmented reality technologies, discussion, and experimentation with various forms of media and learning activities. Lecturers learned how to use the Aurasma software application to embed specific media content in 'overlays' which could be triggered from the surfaces of specific cubes using a mobile device. The diversity of approaches to each discipline provided a rich context for discussion and sharing of design concepts amongst the participants. I also provided specialized support for lecturers in refining, testing, and finalizing their tutorial walk designs via email, skype and face-to-face meetings.

In the Implementation Stage, a series of seven tutorial walk designs were developed to the prototype stage, and implemented through the following undergraduate units in the first semester of 2016:

COM00461: Making Radio: Production Essentials (creative industries)

ART00622: Visual Arts Studio Studies I (arts)

ART00623: Visual Arts Studio Studies III (arts)

ART00625: Visual Arts Studio Studies V(arts)

EDU20008: Human Society and its Environments: Curriculum and Pedagogy (education)

COM40015: Research Methods for Arts and Social Sciences (arts and social sciences)

SCI10002: Science in Society (environmental science)

I provided ongoing technical, design, and pedagogical support for participating lecturers throughout the implementation process. Further details about the implementation stage are reported in the case studies below.

For the Evaluation Stage, a survey instrument was developed to evaluate the impact of the walks on student engagement, conceptual knowledge and practical knowledge. The survey was also designed to identify elements of the walks that impacted the most on student learning experiences, including the elements of walking, technology, learning environments, discussion, and reflection. The survey instrument was voluntarily administered to students, with a response rate of $n=108$. I also collected qualitative data through the documentation of the walks in collaboration with the participating lecturers. This qualitative data included field notes, post-walk reflections from participating lecturers, photographs taken during the walks, and iPad photos captured by students whilst undertaking the walks. The evaluation data was used to inform the preparation of case studies which provide detailed accounts of the design, implementation and evaluation findings for each of the tutorial walks. In the sections below, I briefly discuss two case studies of tutorial walks undertaken in units in Education and Research Methods.

\section{Case Study 1: World Hunger Walk}

The first case study reports on the World Hunger Walk, which was undertaken as part of the subject EDU20008: Human Society and its Environments: Curriculum and Pedagogy. The World Hunger Walk was designed to engage Bachelor of Education students with geographical and ethical issues 
related to the world hunger epidemic. The walk also emphasised the development of students' critical thinking and pedagogical approach to teaching this topic in the Primary school classroom. A series of multimedia data files were developed for two of the Cube locations, including images, maps, statistics, figures, links, discussion questions and activities designed to critically engage students with the topic of world hunger. This content was uploaded to the Aurasma augmented reality application and assigned to the faces of the Mapping and Engagement cubes located near the geography and education faculties respectively. The World Hunger Walk was trialled with two tutorial groups of Bachelor of Education students $(n=40)$. The tutorial walks were delivered by lecturers in education, with 22 students attending the first tutorial walk and 18 students attending the second walk. An initial in-class orientation was provided for the students, including basic instructions on how to download and operate the Aurasma mobile application. Students either used their own personal devices or one of the iPads provided, allowing all students to individually operate the mobile application during the walk.
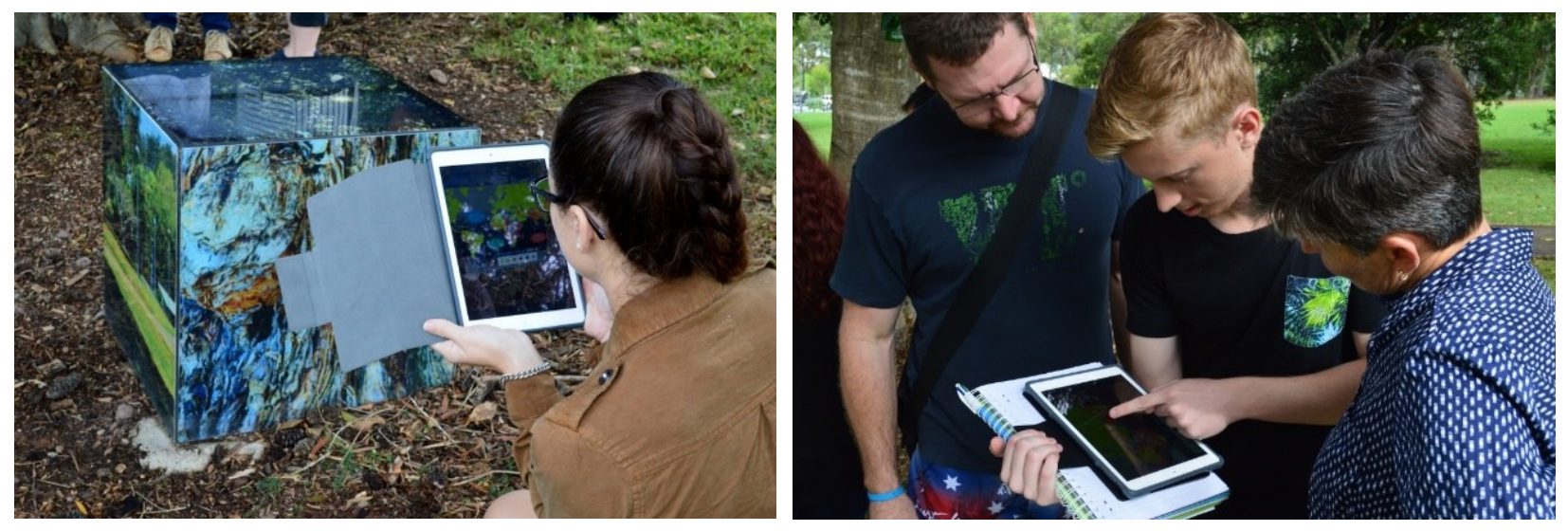

Figure 5: Students triggering multi-sensory data off the Mapping cube's surface, and engaging with other students and tutors around this data

The World Hunger Walk was evaluated through participant observation, visual documentation and the mixed methods survey developed to evaluate the Walking With Media project. The survey was completed by 35 students, with the majority of respondents identifying as female, $3{ }^{\text {rd }}$ year Bachelor of Education students in their early twenties. These three sources of evaluation data indicate that the majority of students were successfully engaged with the tutorial walk, with $67 \%$ of students reporting that they felt highly engaged with the activity. Participant observation and visual documentation also reported high levels of engagement across a range of learning activities. Most students appeared to navigate the technology with ease. Some students showed independence in digitally collecting and archiving the information provided and taking notes. Most students actively participated in all activities and discussions, some requiring more facilitation by the tutor than others. 
Students also reported that the World Hunger walk contributed to their practical learning and skills in the subject area of HSIE Education, and helped them to think differently about their discipline. $50 \%$ of respondents reported that the walk contributed significantly to their practical knowledge, with comments indicating that the walk 'made me aware of alternative pedagogical approaches' and 'showed how to integrate technology and different types of learning in teaching'. $72 \%$ of respondents also confirmed that the tutorial walk helped them think differently about their discipline, with student comments confirming that the tutorial walks 'broadened my thinking'. Participant-observation also reported students clearly thinking about the discipline of education from different perspectives, including the consideration of new educational technologies and media within their teaching practices. Students contributed practical ideas as to how they might engage young children with the issue of world hunger, with an emphasis on active and environmental learning experience associated with school gardens, lunchbox analysis, dramatic simulations, blogging, and critical thinking strategies.

Students also reported that the elements of walking, mobile technology, and social interaction had the greatest impacts on their learning during the World Hunger walk. $66 \%$ of respondents reported that walking contributed or very much contributed to their learning, while $75 \%$ indicated that technology and augmented reality impacted significantly on their learning experiences. Participant-observation also confirmed that students appeared to enjoy the mobility of the tutorial walk, and students frequently commented on the fluidity of social interactions which this format offered for them. As compared to the normal classroom format, the relatively open structure of the walk allowed for increased participation and interaction between students in a less formal arrangement. Students also appeared to enjoy and take advantage of the affordances of the built environment during the tutorial, and their design and discussion of environmental learning activities reflected this influence.

\section{Case Study 2: Sensory Ethnography Walk}

The second case study reports on the Sensory Ethnography Walk that took place as part of the subject COM40015 Research Methods for the Arts and Social Sciences. This is a compulsory subject for all students in the School of Arts and Social Sciences Honours programs. In this program students are working across a range of disciplines - the humanities, social sciences, social welfare, media, creative writing, music, visual arts - and are engaging in research that could be practice-led, critical and/or qualitative. The specific strategy chosen for the walk was to engage in a sensory ethnography of university campus culture (Pink 2009; Pink et al. 2010). Sensory ethnography was selected in order to introduce students from a range of disciplines to ethnography and its underpinning theories, and to bring their range of creative skills to bear on a group exploration of the possibilities for gathering, examining and representing ethnographic data.

The Sensory Ethnography Walk was designed to actively engage students with key aspects of ethnographic research, including participant-observation, fieldwork, interview techniques and 
modes of representation. The walk incorporated three key Cube locations and their associated concepts: Engagement, Mapping and Creativity. A series of PowerPoint slides were developed for each of the Cube locations, each of which featured an evocative photographic image and minimal text providing contextual quotations and instructions for the student's activities. These slides were loaded into the Aurasma augmented reality application and assigned to the faces of the Engagement, Mapping and Creativity cubes. The activity prompts also encouraged students to use the camera functions on their devices to experiment with recording interviews and capturing multimedia data from the built environment. The Sensory Ethnography Walk was trialled with a group of 19 Honours students undertaking research projects in the arts, humanities, and social sciences. Students were provided with an introduction to the topic of sensory ethnography, followed by basic instructions on how to download and operate the Aurasma mobile application. Students were also provided with a printed map of the CubeWalk identifying the specific locations and concepts they would be engaging with during the tutorial walk.
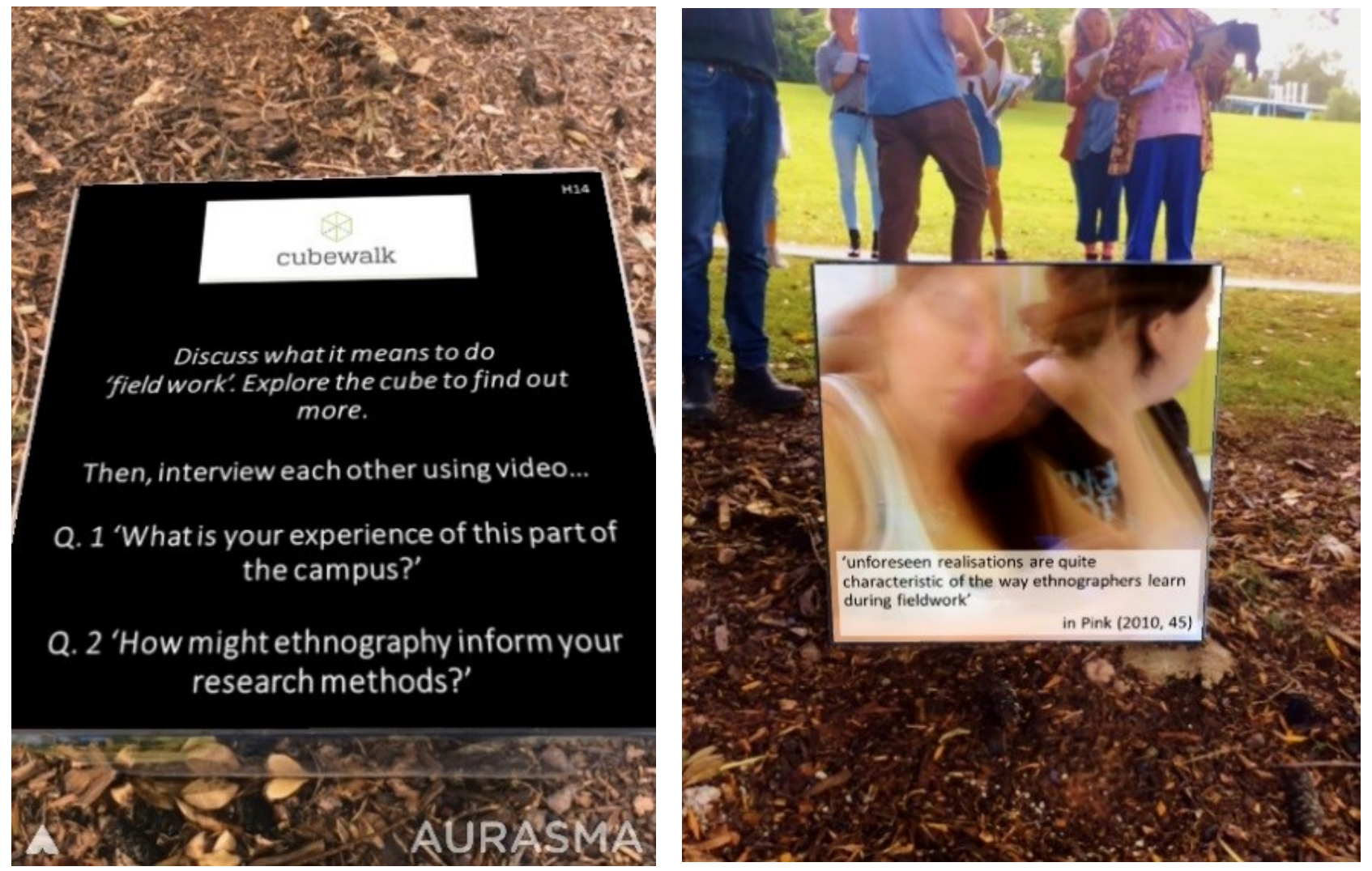

Figure 8: Screenshots captured by students showing the slides triggered at the Mapping cube.

The Sensory Ethnography Walk was evaluated through participant observation, visual documentation and the mixed methods survey developed to evaluate the Walking With Media project. The survey was completed by 18 students, including those undertaking Honours projects in Visual Arts, Music, Cultural Studies, Media Studies and Social Science. The students' age groups were also diverse, ranging from 21-60 years old, and there was a 60/40 split between 
Female and Male respondents. The results of these three sources of evaluation data suggest that nearly all of the students who undertook the Sensory Ethnography walk found the activity highly effective, with $100 \%$ of students reporting high levels of engagement in the post-walk survey. Student comments on their experiences during the walk were consistently positive, with students indicating that they were 'engaged in conversations and the environment' and were 'impressed by the seamlessness'. A number of students also reported an increased sense of 'mindfulness' and 'sensory awareness' of the built environment, and their appreciation of 'having a physical medium' to engage their 'interest in learning'. Participant observation and visual documentation also reported high levels of engagement across a range of learning activities. Most students appeared to navigate the technology with ease, and were able to actively engage with independent and group learning activities without prompting from the tutors. Students demonstrated active and independent learning by collecting and archiving multimedia data and taking field notes in their journals. All students actively participated in the activities and discussions, some requiring more verbal facilitation by the tutor than others.

The evaluation data also suggests that students found that the Sensory Ethnography walk increased their knowledge of ethnographic research methods. $100 \%$ of students who completed the postactivity survey indicated that the walk contributed to their practical and conceptual understandings of ethnography. Student comments suggesting that the activity helped them understand that participatory practices of walking, sensing, and imagining could become part of an ethnographic methodology. For instance, students reported that the tutorial walk 'helped identify ethnographic elements in my Honours project' and 'helped me consider the spaces in which I conduct research and to use my senses when conducting research'. Participant observation also reported students clearly thinking about their disciplines from different perspectives, including the consideration of different methods and modalities of multi-sensory data collection and representation for their research. The tutorial design successfully integrated a range of different environments, technologies and modes of engagement, allowing students' time to absorb and actively explore complex ethnographic concepts and practices.

The element of walking was also identified by students as having significant impact on their learning, as $75 \%$ of respondents reported that walking contributed substantially to their experience of the tutorial. One commented that walking 'gave a sense of movement, social interaction, passing environment, and time for thought', while another suggests that 'the combination of discussion, walking, and environment was different to a classroom... more informal and light hearted'. The significance of walking also confirmed through participant observation, as students clearly appreciated the time spent walking together and discussing their ideas with other students who they did not ordinarily speak with. The element of walking therefore afforded unanticipated social and environmental learning experiences that were reported by students as being extremely beneficial to their understandings of ethnographic research. 


\section{Discussion of Findings}

The findings from these two case studies indicate that both walks effectively contributed to student engagement, social interactions, environmental awareness, practical knowledge and conceptual understanding of unit content. Based on evaluations carried out through surveys and participantobservation, the tutorial walks were highly successful in engaging students with contextual and mobile learning experiences as they moved across the campus. For the most part, students found that the technology was easy to use and were excited by the capacity to engage with multimedia data in connection with the built environment while walking across the campus. The social aspect of the walks was also highlighted in students' responses, as they described how much they enjoyed the capacity for informal movement and sociality afforded by the mobile tutorial format. In many cases, they found themselves forging new relationships with their peers through the mobile learning activities, with the somatic process of walking offering a rearrangement of previously sedimented social interactions. In addition, the students' reported that the immersive and seamless qualities of the tutorial walks increased their motivation to learn and contributed to a sense of connection and potentiality in relation to the surrounding environment. Students described this in terms of 'a physical and mindful space of sensory awareness of the university environment', as augmented by the affordances of mobile technologies that 'helped to engage my interest in learning'.

The case studies also point towards possible directions for future development and research. Findings from the evaluation of both walks indicate that the process of collecting, documenting, archiving and reflecting on the learning experience could be more streamlined and scaffolded by prior readings and activities. In future iterations, students could be trained to use the various functions on their mobile devices prior to the walks, including triggering, collecting and archiving content, taking field notes, annotating maps or other documents, and recording video, audio or photos. This should also be considered in the structural design of the tutorial walk itself, such that students are aware that they will be collecting a range of 'multimedia data' embedded in the campus environment, and that they will have the opportunity to interpret and reflect on that data following the walk. Several students also expressed interest in having the augmented reality content updated regularly, and for the walks to integrate a greater diversity of campus environments. These comments gesture towards the potentials for the CubeWalk to be extended into a more expansive infrastructure that is utilised not only by the university community, but also by members of the wider public and local communities that visit the university campus.

\section{Conclusion: Towards a mixed reality pedagogy}

The first part of this chapter outlined a theoretical framework for a mixed reality pedagogy that integrates environmental theories of learning, relational architecture, and $21^{\text {st }}$ century media technologies. The second part of the chapter has described the context, design and functioning of the CubeWalk network, and the evaluation of immersive tutorial walks that were undertaken through the Walking with Media project. Taken together, the conceptual and architectural 
infrastructure of the CubeWalk and its curricular application through tutorial walks constitute a fundamental re-imagining of the pedagogical capacities afforded by the learning environments of the $21^{\text {st }}$ century university. The CubeWalk network has introduced new pedagogical affordances into the built environment of a university campus that simply were not there before. These affordances can be understood as pedagogical to the extent that they have had significant effects on how teaching and learning can actually take place on the campus. Seminars and tutorials can now be experienced while walking the campus and interacting with outdoor learning environments that are seeded with multimedia data, rather than being confined to the interior spaces of lecture theatres and classrooms. As demonstrated in the case studies above, students and academics have come to see the potentials of the whole campus as an environment for learning, rather than being bounded by the habitual limitations of disciplinary territories and conventional teaching approaches. This can be understood as a transition from a territorialised and sedentary pedagogy of stasis, habit, certainty, and convention to a distributed and nomadic pedagogy of radical openness, uncertainty, mobility, and mixed realities. By combining a network of strategic architectural installations with learning designs that capture and redirect multimedia data across the campus, the Walking with Media project has contributed to the development of a 'mixed reality pedagogy' that opens up new connections between learning, media technologies, and the built environment.

As noted at various points throughout this chapter, the issue of how personal data is generated, collected, deployed and conceptualised is of central concern to the development of a mixed reality pedagogy. The theoretical and practical move to render personal data as diffuse, elemental, and atmospheric brings important ethical considerations to bear on the increasing digitisation, decentralisation and datification of universities in the $21^{\text {st }}$ century. Within this context of increasing porosity and transparency with respect to bodies, buildings and digital media network, the CubeWalk offers an alternative model through which personal data becomes environmental in ways that are artful, pedagogical, and theoretically generative. By locating and diffusing personal data within specific places and times of encounter, the CubeWalk enables people to put their personal data to work in ways that are potentially empowering and co-productive. This pushes back at the algorithmic capture of personal data by computational systems and social media platforms that are designed to exert governmental, social, and market control. The mixed reality pedagogy that is developed and prototyped through the CubeWalk network thus affirms an alternative vision of personal data as collectively produced and encountered within a sensory ecology. This shifts the ontology as well as the pragmatics of data towards the figure of the learning environment as a relational architecture, such that learning and data become intricately connected elements within a co-constituted assemblage of mixed milieus and heterogeneous modes of existence.

By way of concluding this chapter, I would like to address the reconceptualisation of 'teaching' that arises from the proposition of a 'mixed reality pedagogy', while also gesturing towards further research in this area. One of the key theoretical issues that the Walking with Media project raises 
is the question of pedagogical agency with respect to the design and implementation of immersive learning activities that integrate multimedia data with the built environment. Indeed, the lecturers who designed and accompanied their students on the walks found themselves in the unusual position of being displaced from the front of the classroom, wondering whether or how much to interfere with the learning process, and inevitably becoming a minor facilitator of the walk's unfolding rather than occupying the traditional teaching role. The Walking with Media project thus raises the question of how a 'mixed reality pedagogy' might transform the concept and practice of 'teaching' within $21^{\text {st }}$ century learning environments. In a similar way that the concept of 'learning' was theorised as an environmentally distributed process in the earlier sections of this chapter, we might also begin to consider 'teaching' as a decentralised agential force that inheres to bodies, buildings, landscapes, media, and more. This theorisation fits with Ellsworth's (2005) vision of 'places of learning' which come together through the dynamic interactions between architecture, design, media, sensation, and pedagogy. For Ellsworth, pedagogy is tied to the question of how learning environments are collectively designed, sensed, activated and mobilised 'in ways that modulate intensity, rhythm, passage through space, duration through time, aesthetic experience, and spatial expansion and compression' (p. 42). In this sense, a mixed reality pedagogy is defined by the distributed composition and 'mixture' of heterogeneous pedagogical elements, including elements of time, space, movement, sensation, mediation, sociality, embodiment, and aesthetic experience.

In line with the findings of the Walking with Media project, a mixed reality pedagogy places an emphasis on pedagogical design as the spatio-temporal arrangement and composition of pedagogical elements and open-ended provocations that are conducive to learning experiences in specific places and times. The role of pedagogical delivery is thus de-emphasised, or at least displaced to become just one of many elements in the sensory manifold and emergent operationality of a mixed reality pedagogy. The attribution of pedagogical agency to the built environment and media technologies dynamically shifts the role of the educator, such that the teacher becomes one of many elements or gears in a more widely distributed pedagogical assemblage or machine (Rousell \& Fell, 2018). Within a mixed reality pedagogy, the role of the educator may come closer to that of the relational artist, designer, or architect who brings concepts, places, people, technologies, data, and media together in order to foster a 'distributed architecture of experience' (Massumi, 2011, p. 53). As considered under the influence of such an ecological theory of learning, the function of educational design and indeed of educational architecture also becomes speculative and processual in nature. Rather than the application and testing of preformulated design principles or hypotheses, a mixed reality pedagogy comes to involve the fostering and dynamic modulation of collective movements and potentials for learning which can never be determined in advance. While such learning processes cannot be designed in advance of the event, they can designed-for and designed-with the speculative potentialities of learning as a process that is conditioned, modulated, and augmented by environmentally distributed forces, technologies, and agencies. 


\section{References:}

Bacca, J., et al. (2014). Augmented reality trends in education: a systematic review of research and applications. Journal of Educational Technology \& Society 17(4), 133.

Baran, E. (2014). A Review of Research on Mobile Learning in Teacher Education. Educational Technology \& Society 17(4), 17-32.

Bower, M., et al. (2014). Augmented Reality in education-cases, places and potentials. Educational Media International, 51(1), 1-15.

Brown, G. (2009). The ontological turn in education: The place of the learning environment. Journal of Critical Realism, 34(5), 5-36.

de Freitas, E. (2011). Parkour and the built environment: Spatial practices and the plasticity of school buildings. JCT (Online), 27(3), 209.

Deleuze, G. (1994). Difference and repetition (P. Patton, Trans.). New York, NY: Columbia University Press.

Dovey, K., \& Fisher, K. (2014). Designing for adaptation: The school as socio-spatial assemblage. The Journal of Architecture, 19(1), 43-63.

Ellsworth, E. (2005). Places of learning: Media, architecture, pedagogy. Abingdon, UK: Routledge.

Frost, S. (2016). Biocultural creatures: Toward a new theory of the human. Durham, NC: Duke University Press.

Gibson, J.J. (1979). The ecological approach to visual perception. Boston, MA: Houghton Mifflin.

Gislason, N. (2010). Architectural design and the learning environment: A framework for school design research. Learning Environments Research, 13(2), 127-145.

Guattari, F. (2008). The three ecologies. London, UK: Continuum.

Hall, T. (2017). Architecting the 'third teacher': Solid foundations for the participatory and principled design of schools and (built) learning environments. European Journal of Education, 52(3), 318-326. 
Hansen, M.B. (2015). Feed-Forward: On the future of $21^{\text {st }}$ Century media. Chicago, IL: University of Chicago Press.

Hertzberger, H. (2008). Space and learning. Rotterdam: 010 Publishers.

Hewlett Packard Company. (2016). HP Aurasma is changing the way we interact with the world. Retrieved 21 November, 2017 from https://www.aurasma.com/

Ho, C. M. L., Nelson, M. E., \& Müeller-Wittig, W. (2011). Design and implementation of a student-generated virtual museum in a language curriculum to enhance collaborative multimodal meaning-making. Computers \& Education, 57(1), 1083-1097.

Jiménez, A. C. (2014). The right to infrastructure: A prototype for open source urbanism. Environment and Planning D: Society and Space, 32(2), 342-362.

Keifer-Boyd, K., Knochel, A. D., Patton, R. M., \& Sweeny, R.W. (2018). Posthumanist Movement Art Pedagogy: Geolocative Awareness and Co-Figurative Agency With Mobile Learning, Studies in Art Education, 59(1), 22-38.

Kelly, A. E., Lesh, R. A., \& Baek, J. Y. (2008). Handbook of design research methods in education. [Innovations in science, technology, engineering, and mathematics learning and teaching]. New York: Routledge.

Leiringer, R., \& Cardellino, P. (2011). Schools for the twenty-first century: school design and educational transformation. British Educational Research Journal, 37(6), 915-934.

Livingstone, S. (2012). Critical reflections on the benefits of ICT in education. Oxford review of education, 38(1), 9-24.

Margulis, L. (1999). The symbiotic planet: A new look at evolution. London, UK: Phoenix.

National Foundation for Educational Research (NFER). (2017). FutureLab at NFER. Retrieved August 14, 2017 from https://www.nfer.ac.uk/futurelab/.

OECD (2006) PEB Compendium of Exemplary Educational Facilities, 3rd edn. Organization for Economic Cooperation and Development (Paris, OECD Publishing).

Oliver, M. (2011), Technological determinism in educational technology research: some alternative ways of thinking about the relationship between learning and technology. Journal of Computer Assisted Learning, 27, 373-384.

Parisi, L. (2009). Technoecologies of sensation. In B. Herzogenrath (ed.), Deleuze| Guattari \& Ecology (pp. 182-199). Hampshire, UK: Palgrave Macmillan. 
Peters, M.A., \& Besley, T. (2013). Introduction: The creative university. In M.A. Peters \& T. Besley (Eds.), The creative university (pp. 1-8). Rotterdam, ND: Sense Publications.

Pink, S. (2009). Doing sensory ethnography. London: Sage.

Pink, S., Hubbard, P., O'Neill, M., \& Radley, A. (2010). Walking across disciplines: from ethnography to arts practice. Visual Studies, 25(1), 1-7.

Rogers, Y., Price, S., Fitzpatrick, G., Fleck, R., Harris, E., Smith, H., ... \& Thompson, M. (2004). Ambient wood: designing new forms of digital augmentation for learning outdoors. In Proceedings of the 2004 conference on Interaction design and children: building a community (pp. 3-10). ACM.

Rousell, D., \& Fell, F. (2018). Becoming a Work of Art: Collaboration, materiality and posthumanism in tertiary visual arts education. International Journal of Education Through Art [special issue on Speculative Realisms in Arts Education], 14(1), 91-110.

Rousell, D. (2017). Mapping the data event: A posthumanist approach to art|education|research in a regional university. In L. Knight \& A. L. Cutcher (eds.). Arts, research, education: Connections and directions, (pp. 203-220). New York: Springer International Publishing.

Rousell, D. (2016). Dwelling in the Anthropocene: Re-imagining university learning environments in response to social and ecological change. The Australian Journal of Environmental Education, $32(2), 137-153$.

Rousell, D. (2015). The cartographic network: Re-imagining university learning environments through the methodology of immersive cartography. UNESCO Observatory Multidisciplinary Journal in the Arts [Special issue on Critical Approaches to Arts-Based Research], 5(1), 1-33.

Sharples, M., Arnedillo-Sánchez, I., Milrad, M., \& Vavoula, G. (2009). Mobile learning: Small devices, big issues. In S. Ludvigsen, N. Balacheff, T. D. Jong, A. Lazonder, and S. Barnes (Eds.), Technology-enhanced learning: Principles and products (pp. 233-249). Berlin, Germany: Springer-Verlag.

Shaviro, S. (2009). Without criteria: Kant, Whitehead, Deleuze, and aesthetics. Cambridge, MA: MIT Press.

Simondon, G. (1958/2017). On the mode of being of the technical object. (Trans. C. Malaspina \& J. Rogove). University of Minnesota Press.

Stanton, D., O'Malley, C., Fraser, M.C., Ng, K.H. and Benford, S.D. (2003). Situating historical events through mixed reality: adult-child interactions in the storytent. In: Proceedings of the International Conference on Computer Support for Collaborative Learning (CSCL) 293-302.

Whitehead, A.N. (1978). Process and reality. New York: The Free Press. 
Willis, J. (2017). Architecture and the school in the twentieth century. In K. Darian-Smith \& J. Willis. Designing schools: Space, place and pedagogy (pp. 1-8). New York: Routledge.

Winnicott, D. W. (1989). Playing and reality. New York, NY: Routledge.

Wood, A. (2017). A School's Lived Architecture: the politics and ethics of flexible learning spaces. Unpublished PhD thesis, Manchester Metropolitan University.

Woolner, P., Clark, J., Hall, E., Tiplady, L., Thomas, U., \& Wall, K. (2010). Pictures are necessary but not sufficient: Using a range of visual methods to engage users about school design. Learning Environments Research, 13(1), 1-22.

Youdell, D. (2017). Bioscience and the sociology of education: the case for biosocial education. British Journal of Sociology of Education. 